\title{
Dorsal hand reconstruction with radial artery perforator-based adipofascial flap
}

\author{
Sho Yamakawa, Kenji Hayashida \\ Division of Plastic and Reconstructive Surgery, Shimane University Hospital, Izumo, Shimane 693-8501, Japan.
}

Correspondence to: Dr. Sho Yamakawa, Division of Plastic and Reconstructive Surgery, Shimane University Hospital, 89-1 Enyacho, Izumo, Shimane 693-8501, Japan. E-mail: yamakawashoright@yahoo.co.jp

How to cite this article: Yamakawa S, Hayashida K. Dorsal hand reconstruction with radial artery perforator-based adipofascial flap. Plast Aesthet Res 2020;7:24. http://dx.doi.org/10.20517/2347-9264.2020.20

Received: 7 Feb 2020 First Decision: 21 Apr 2020 Revised: 25 Apr 2020 Accepted: 28 Apr 2020 Published: 11 May 2020

Science Editor: Alessandro Thione Copy Editor: Jing-Wen Zhang Production Editor: Jing Yu

\begin{abstract}
Reconstruction of dorsal hand soft tissue defects after severe injury is challenging for surgeons. Depending on the degree of defect, extensor tendon reconstruction may also be necessary. Various reconstruction methods are commonly performed to cover dorsal hand defects, such as skin grafting and distant, free, or local flaps. Among them, free vascularized flap transplantation is an ideal procedure because the major vessels that feed the local flap may have been damaged, and the affected limb can be reconstructed using a flow-through method. Although free flap surgery has advanced, few surgeons can choose this option due to its technical difficulty and uncertainty. On the other hand, distant flaps have been commonly used for the reconstruction of dorsal hand defects, and local flaps, such as reverse forearm flaps and retrograde posterior interosseous flaps, do not require microvascular anastomosis. However, they have some problems; distant flaps require at least two surgeries, reverse forearm flaps sacrifice major vessels and leave a scar at the donor site, and retrograde posterior interosseous flaps require meticulous dissection of the vascular pedicle. The radial artery perforator-based adipofascial flap is a versatile flap that is safe and easy to elevate without sacrificing the radial artery. In addition, elevating it as an adipofascial flap enables surgeons to avoid an unacceptable donor scar. We present two cases, demonstrating the usefulness of this pedicled perforator flap.
\end{abstract}

Keywords: Perforator, dorsal hand reconstruction, adipofascial flap, hand replantation, color Doppler ultrasonography 


\section{INTRODUCTION}

Soft tissue defects of the dorsal hand are commonly caused by relatively high-energy trauma such as industrial accidents. In such cases, free vascularized flap transplantation is the ideal procedure because the major vessels in the zone of injury that may have been damaged, and the vascular supply of the flap and affected limb can be reconstructed using a flow-through method ${ }^{[1]}$. Although free flap surgery has advanced, not all surgeons can select this complicated procedure. Recently, several surgeons have reported local flap procedures for the reconstruction of dorsal hand defects ${ }^{[2,3]}$. Among them, the reverse radial forearm flap is a common method for the treatment of dorsal hand injuries ${ }^{[4]}$. This flap is reliable in regards to vascular supply; however, the main vessels of the forearm and hand must be sacrificed. Thus, this flap cannot be used, if Allen's test shows an incomplete palmar arch. Moreover, unacceptable donor site morbidity is a major drawback of this flap. The posterior interosseous flap is also an effective option ${ }^{[5,6]}$. Although this flap enables covering the dorsal hand defect with well-vascularized tissue without sacrificing major vessels, it requires surgeons to perform fine and burdensome procedures. The radial artery perforator based adipofascial flap is a versatile flap that is safe and easy to elevate without sacrificing the radial $\operatorname{artery}^{[7,8]}$. In addition, elevating it as an adipofascial flap enables surgeons to avoid an unacceptable donor scar. We present two case reports demonstrating the usefulness of this pedicled perforator flap for dorsal hand reconstruction.

\section{ANATOMY AND PREOPERATIVE EVALUATION}

Before flap elevation, contrast-enhanced computed tomography and/or color Doppler ultrasonography of the affected forearm were performed to evaluate the blood circulation of radial vessels. Using color Doppler ultrasonography, Onode et al..$^{[9]}$ reported that an average of six fasciocutaneous perforators arising from the distal radial vessels can be observed within $15 \mathrm{~cm}$ proximal to the distal wrist crease. There are two or more clinically significant $(>0.5 \mathrm{~mm})$ cutaneous perforators at the pivot point within $2 \mathrm{~cm}$ proximal to the radial styloid ${ }^{[8]}$. The adipofascial flap on the lateral aspect of the distal forearm is raised proximal to distal, including the lateral antebrachial cutaneous nerve and the cephalic vein. Although a number of surgeons have reported using this flap, there is no consensus regarding the maximum safe longitudinal flap size. In our opinion, it can be the length of the forear, because as Taylor et al. ${ }^{[10]}$ reported, designing the flap in the longitudinal direction along the cutaneous nerve and the cutaneous vein, blood circulation of a perforasome composed of multiple perforators connected to each other by a true anastomosis can be stabilized. Therefore, including the lateral antebrachial cutaneous nerve and the cephalic vein within the flap enables the distal perforator-based adipofascial flap to be applied safely [Figure 1A and B].

\section{SURGICAL PROCEDURE OF RADIAL ARTERY PERFORATOR-BASED ADIPOFASCIAL FLAP TRANSFER}

1. Design a rectangular adipofascial flap along the radial artery sufficient to cover the defect. An S-shaped skin incision is favorable in consideration of the convenience of fascial flap dissection and direct closure of the skin [Figure 2A].

2. Dissect the subcutaneous plane sufficiently deep to avoid skin necrosis, leaving the dorsal forearm cephalic vein on the adipofascial flap.

3. After incising the proximal edge of the adipofascial flap, dissect the sub-fascial flap from the proximal to distal direction. Several perforators arising from radial vessels can be found in the distal one-third of the forearm. Next, elevate the flap through the intertendinous septum in the middle of the flexor carpi radialis, abductor pollicis longus, and brachioradialis tendons, and enter the fascia of the forearm. Under direct observation, at least one perforator entering the flap must be preserved around the styloid, which is a pivot point [Figure 2B]. 
A

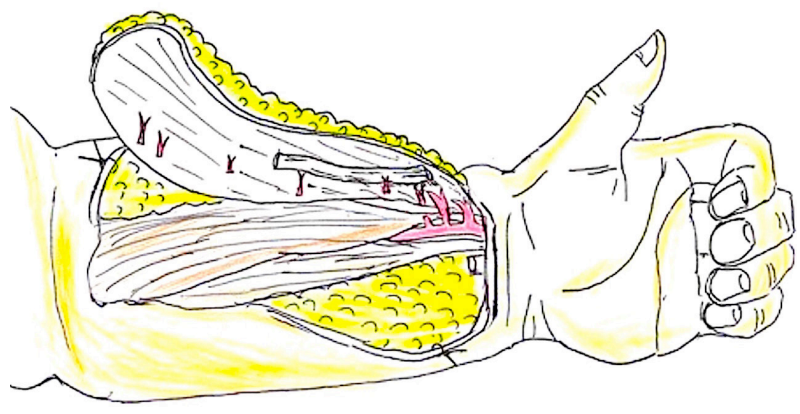

B

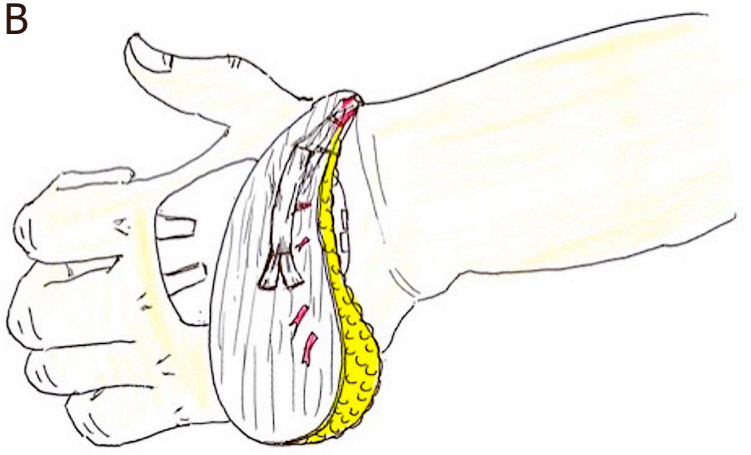

Figure 1. A, B: illustration of radial artery perforator-based adipofascial flap elevation, including connection of both perforators to the subdermal vascular network in the proximal and distal ends of the forearm. This flap can be elevated and transferred to the defect of the dorsal hand safely
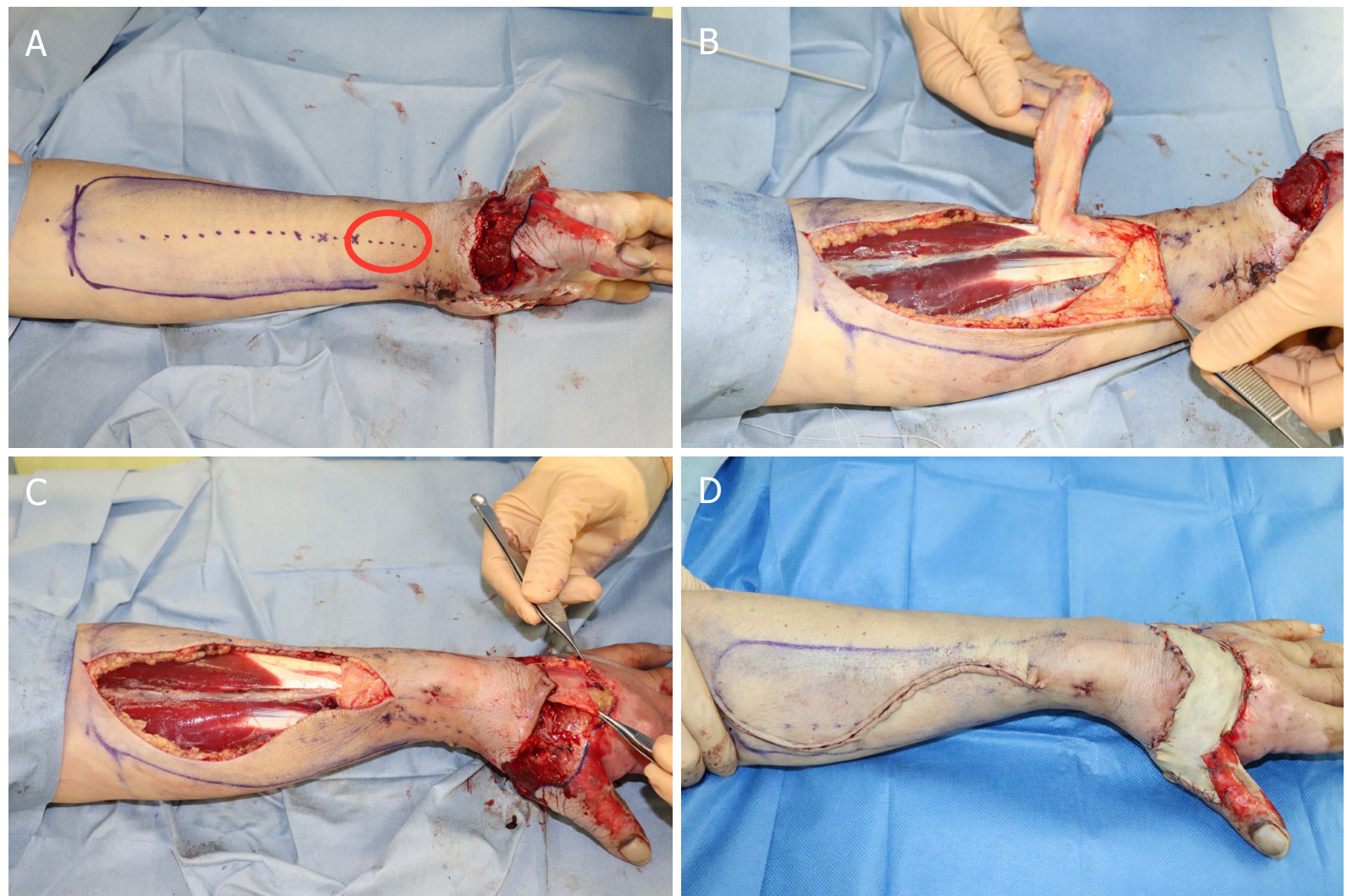

Figure 2. Procedure of radial artery perforator-based adipofascial flap elevation (From Case 1 in this article). A: the radial forearm adipofascial flap was designed along the radial artery. Red circle indicates pivot port; B: the adipofascial flap was elevated, preserving perforators at the distal end of the flap; C: once elevated, the flap was turned over or rotated to reach the dorsal defect; D: the donor site was closed and a skin graft was applied over the flap

4. Transfer the flap through the subcutaneous tunnel to the dorsal hand defect [Figure $2 \mathrm{C}$ ].

5. Resurface the transferred fascial flap on the dorsal hand with a split-thickness skin graft [Figure 2D]. Elevate the affected arm and bandage with slight pressure to avoid postoperative congestion. 

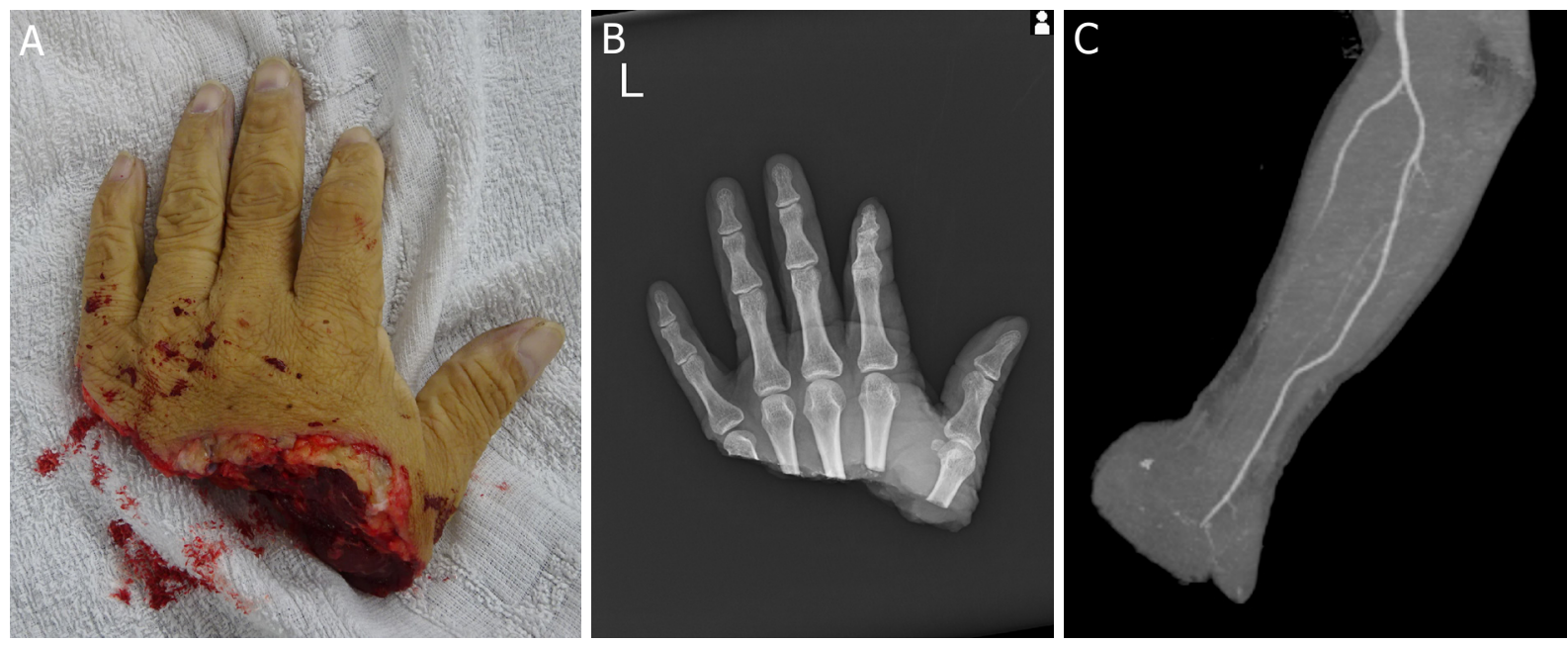

Figure 3. A 43-year-old male smoker with left hand amputation. A: amputated left hand; B: on X-ray, the left hand was completely cut at the metacarpal level; C: contrast-enhanced computed tomography showed poor blood circulation of the radial artery in the distal forearm

\section{CASE REPORTS}

\section{Case 1: reconstruction after hand replantation}

A 43-year-old man had his hand amputated. He accidentally cut his non-dominant left hand with an electric saw while cutting wood [Figure 3A]. His left hand was amputated at the metacarpal level. $\mathrm{X}$-ray examination and contrast-enhanced computed tomography of the affected limb were performed [Figure $3 \mathrm{~B}$ and $\mathrm{C}$ ]. The surfaces of both parts were crushed and severely damaged. Hand replantation surgery was performed under general anesthesia. After bone fixation and tendon repair, microvascular anastomosis was performed. The ulnar side of the palmar arterial was repaired, but not the radial side because the flow through the radial artery was insufficient. Venous repair was performed by vein grafting into three dorsal hand cutaneous veins. The dorsal hand defect after debridement of crushed skin was covered by artificial dermis. The amputated hand survived. Seventeen days after hand replantation surgery, the second operation for reconstruction of the dorsal hand tissue defect was performed. As contrastenhanced computed tomography after hand replantation surgery revealed an incomplete palmar arch, the combination of a radial artery perforator adipofascial flap and split-thickness skin graft was selected. The radial artery perforators were identified using color Doppler ultrasonography and demarcated on the skin [Figure 4]. There was a $4-\mathrm{cm} \times 7-\mathrm{cm}$ defect over the dorsal hand with exposure of extensor digitorum tendons after debridement of necrotized tissue. A lazy S-shaped longitudinal incision on the forearm was designed [Figure 5A]. An $18-\mathrm{cm} \times 5-\mathrm{cm}$ radial artery perforator-based adipofascial flap was elevated. As a vascular pedicle, the distal radial artery fasciocutaneous perforator was left with the soft tissue around the styloid process [Figure 5B]. The flap was turned over and transferred to the defect. A skin graft was immediately placed over the flap. The donor site of the flap was closed [Figure $5 \mathrm{C}$ ]. The postoperative course was uneventful. The flap and skin graft took completely. Half a year after surgery, the skin of the reconstructed dorsal hand was thin and pliable [Figure $6 \mathrm{~A}$ and $\mathrm{B}$ ]. In addition, there was no restriction in the mobility of the wrist or forearm [Figure $6 \mathrm{C}$ and $\mathrm{D}$ ]. However, the thumb-index finger web space was narrow due to poor thumb bone healing caused by poor blood supply. A free flap transfer to the thumbindex finger web space is planned in the next surgery.

\section{Case 2: functional reconstruction of index finger extension}

A 62-year-old man accidentally injured his non-dominant left hand while shaving wood. Skin and soft tissue defects were observed, in addition to exposure of the second metacarpal bone head on the dorsal side 


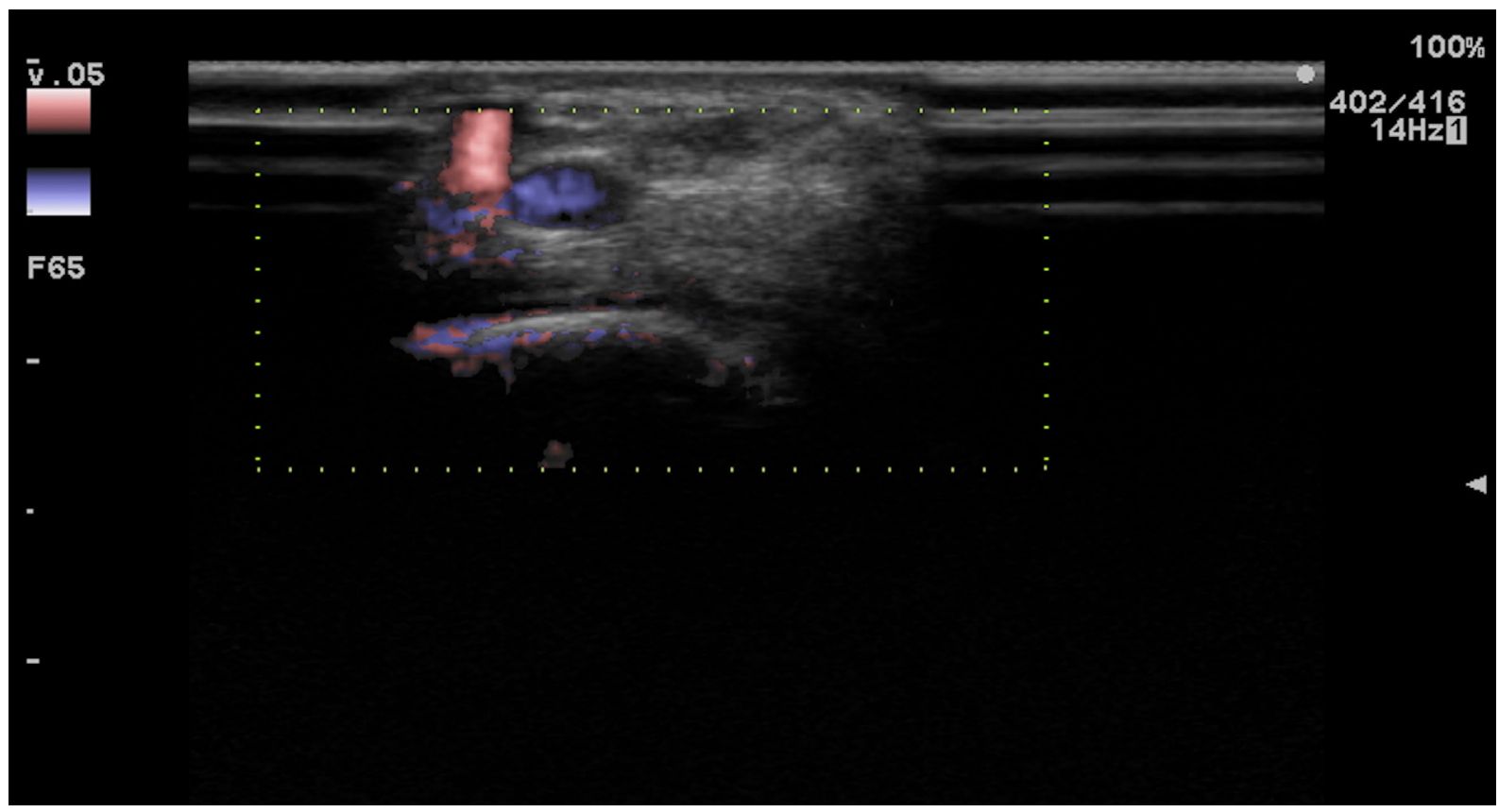

Figure 4. Preoperative color Doppler ultrasonography showed a perforator arising from the radial artery. The perforator was $1.8 \mathrm{~mm}$ in diameter. Most of the fasciocutaneous perforators were within $2 \mathrm{~cm}$ proximal to the styloid

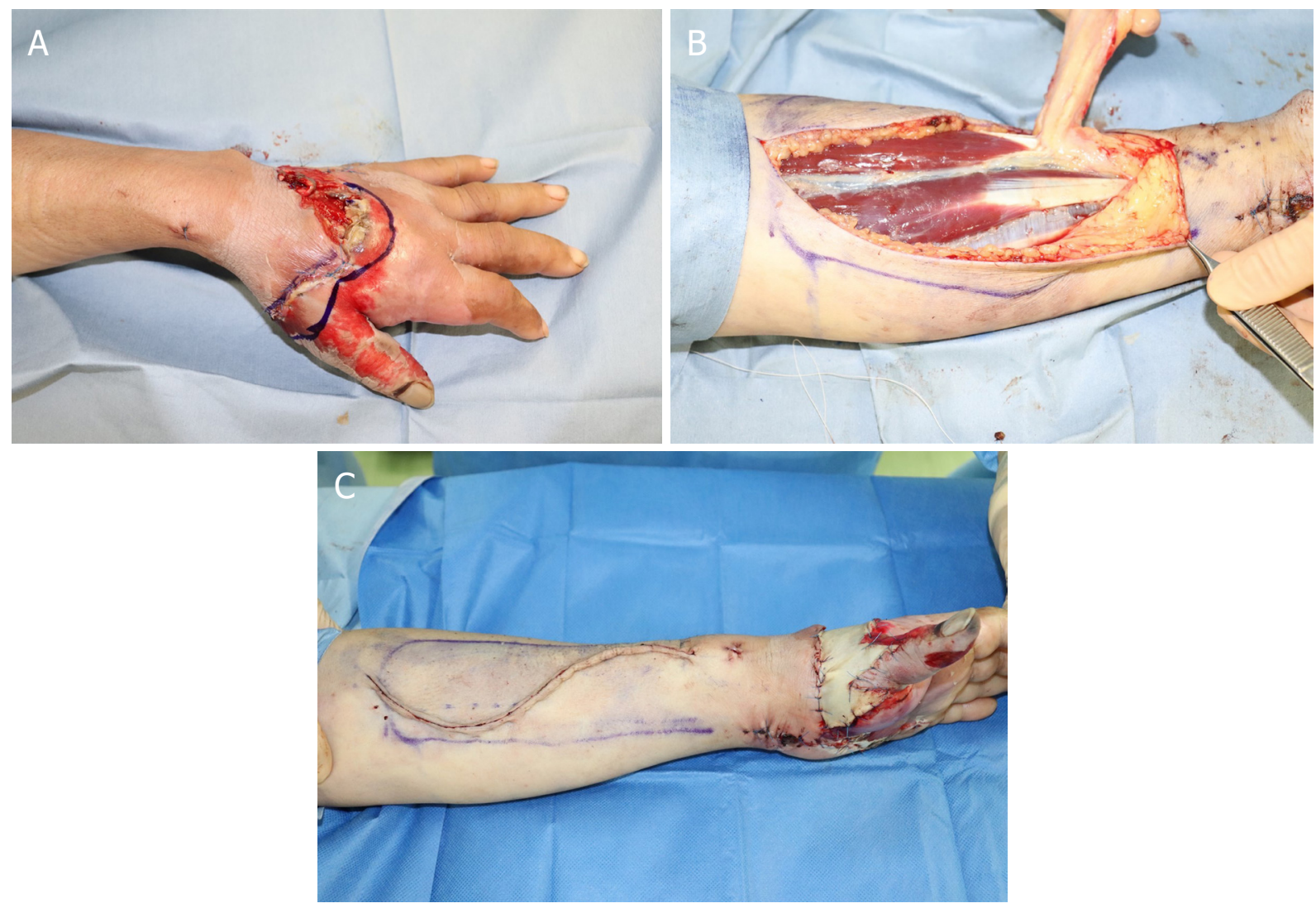

Figure 5. A 43-year-old man 17 days after hand replantation surgery. A: a soft tissue defect of the dorsal hand still remains with exposure of bones and tendons; B: a distally based adipofascial perforator flap was raised from proximally to distally; C: a skin graft was applied over the flap and the donor site was closed 

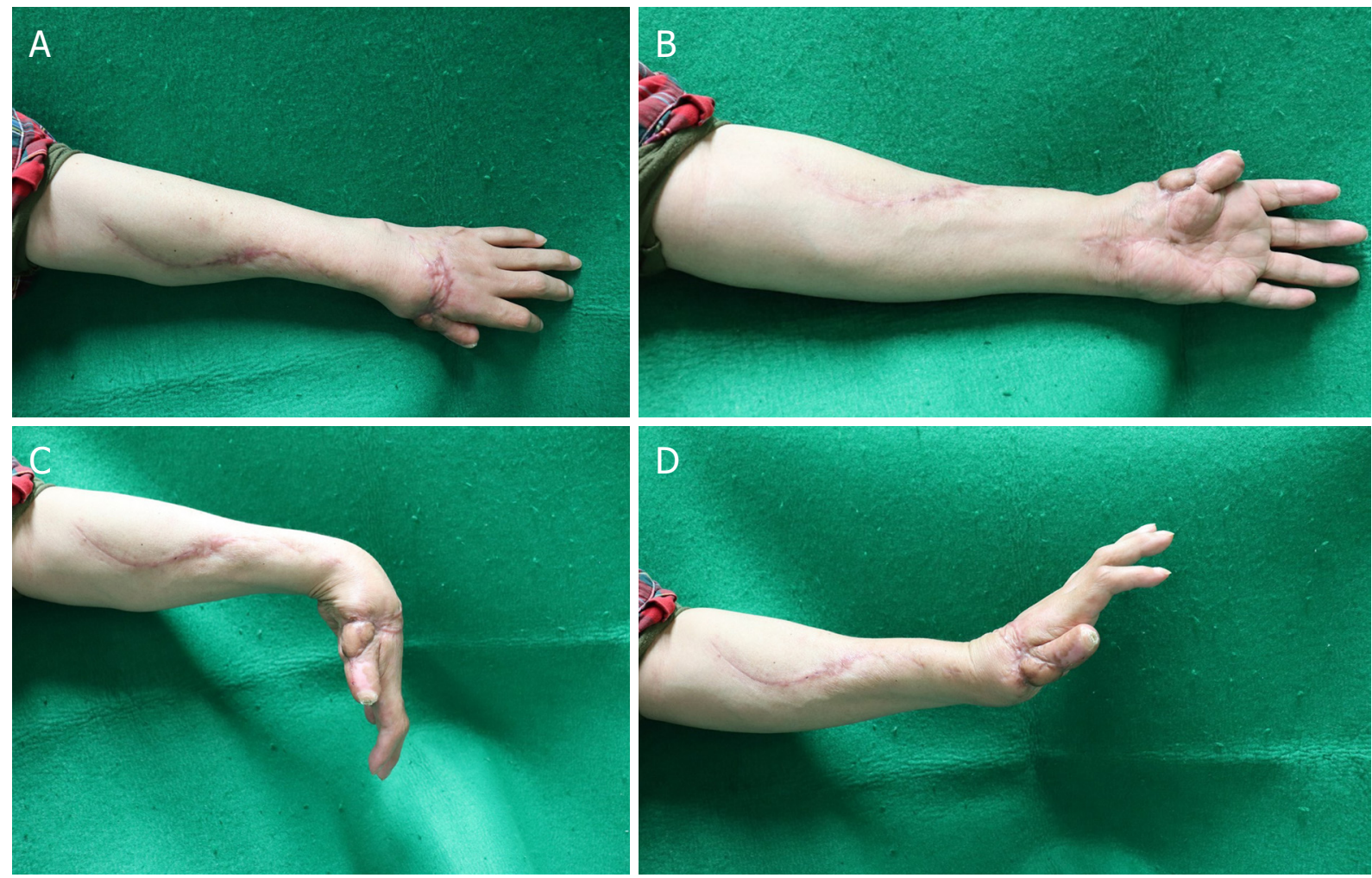

Figure 6. A 43-year-old man 6 months after dorsal hand reconstructive surgery. A, B: the reconstructed skin of the dorsal hand was thin and soft and the donor site was inconspicuous; C, D: the forearm had no adhesion and little restriction of the wrist

[Figure 7A]. Emergency reconstructive surgery was performed. The radial artery perforators were identified using color Doppler ultrasonography. Following marked water lavage and debridement of necrotized soft tissue of the dorsal hand, there was a $6-\mathrm{cm} \times 3-\mathrm{cm}$ defect over the dorsal radial hand. [Figure 7B]. A $10-\mathrm{cm} \times 5-\mathrm{cm}$ distally radial artery perforator-based adipofascial flap was elevated. The palmaris longus tendon was included in the adipofascial flap to reconstruct the extension function of the index finger [Figure $7 \mathrm{C}$ ]. As a vascular pedicle, the distal radial artery fasciocutaneous perforator was left with the soft tissue around the styloid process. The flap was transferred to the defect and the tendon was sutured with the extensor indicis muscle tendon using the interlacing suture technique [Figure 7D]. The tension strength of the tendon suture was adjusted in a functional position. The exposed metacarpophalangeal joint was simply covered with the adipofascial flap. A split-thickness skin graft from the thigh was placed over the flap and the donor of the flap was closed [Figure $7 \mathrm{E}$ and F]. After 3 weeks, the skin graft survived and rehabilitation using a dynamic splint was started. Ten months after surgery, index finger joint movement was slightly restricted. However, there was no problem in daily life and the color matching of the skin graft was good [Figure $8 \mathrm{~A}-\mathrm{C}]$.

\section{DISCUSSION}

Reconstruction of dorsal hand tissue defects after hand injury is challenging for surgeons because of the exposure of blood vessels, nerves, tendons, and bones. Thus, skin grafts are not suitable for use in reconstruction in the case of severe injuries. Furthermore, the palmar arch may not be reconstructed after hand reconstruction, as in our case. In such cases, vascular insufficiency of the limb and flap may develop using retrograde-flow pedicle flaps ${ }^{[11]}$. Therefore, flap options that do not require retrograde blood flow are needed. In case 1, the radial artery perforator-based adipofascial flap was selected for reconstruction of a dorsal hand defect after hand replantation. When soft tissue of the dorsal hand is crushed and extensor 

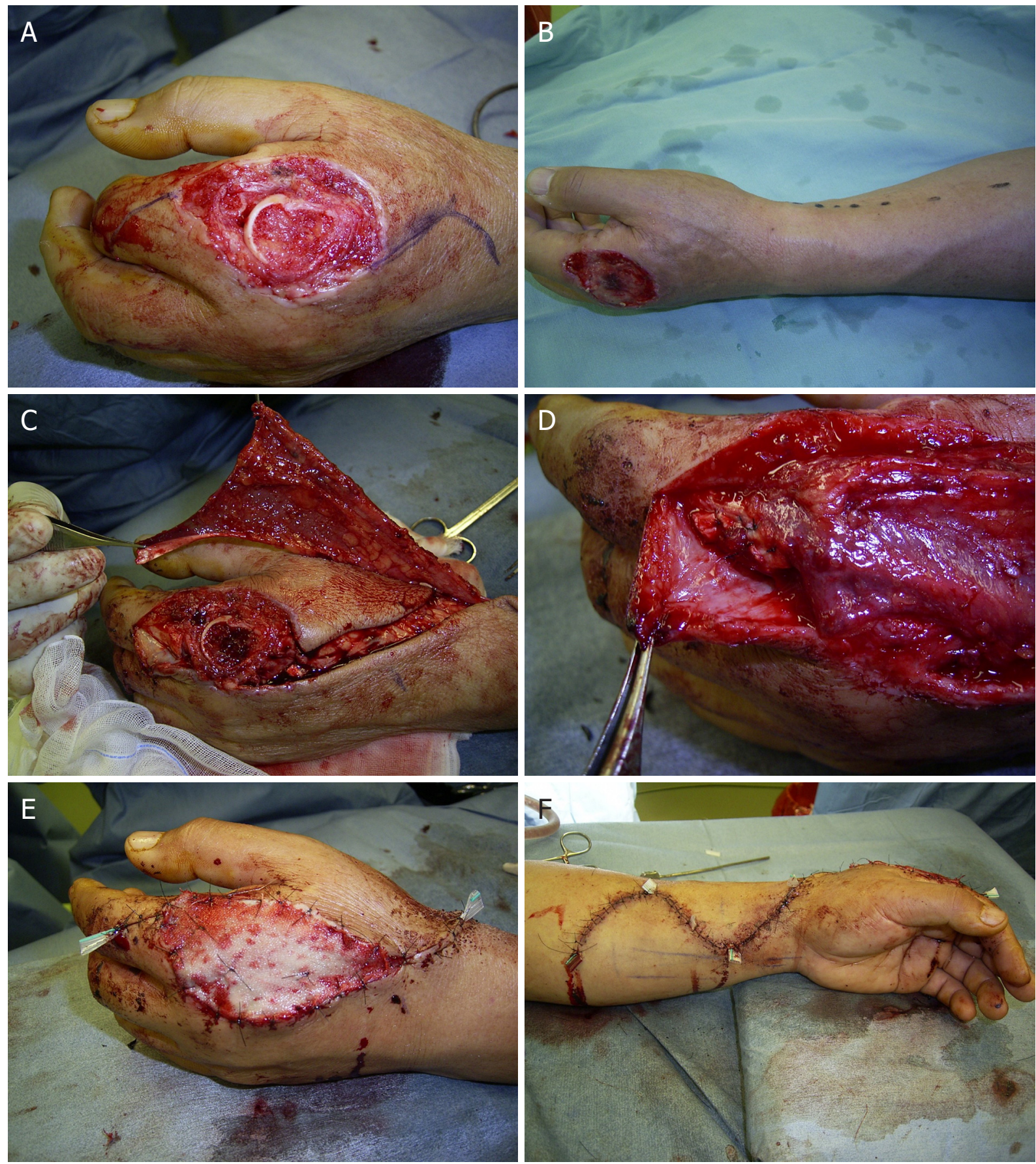

Figure 7. A 62-year-old man with skin and extensor tendon avulsion on the dorsum of his index finger. A: the index MP joint was exposed; B: design of the forearm adipofascial flap along the radial artery; C: raising of the forearm adipofascial flap, including the palmaris longus tendon; D: interlacing suturing of the extensor digitorum tendon and palmaris longus tendon; E: split-thickness skin grafting over the adipofascial flap; F: the flap donor defect was closed

tendons or bones are exposed or lost, soft tissue reconstruction using a flap with good circulation is required to resurface the defect. We were able to reconstruct the defects of blood vessels, nerves, and tendon by the adipofascial flap with forearm tissue. In case 2, the radial artery perforator adipofascial flap with the palmaris longus tendon was selected for reconstruction of the dorsal hand defect and the defect of the extensor indicis muscle tendon. 

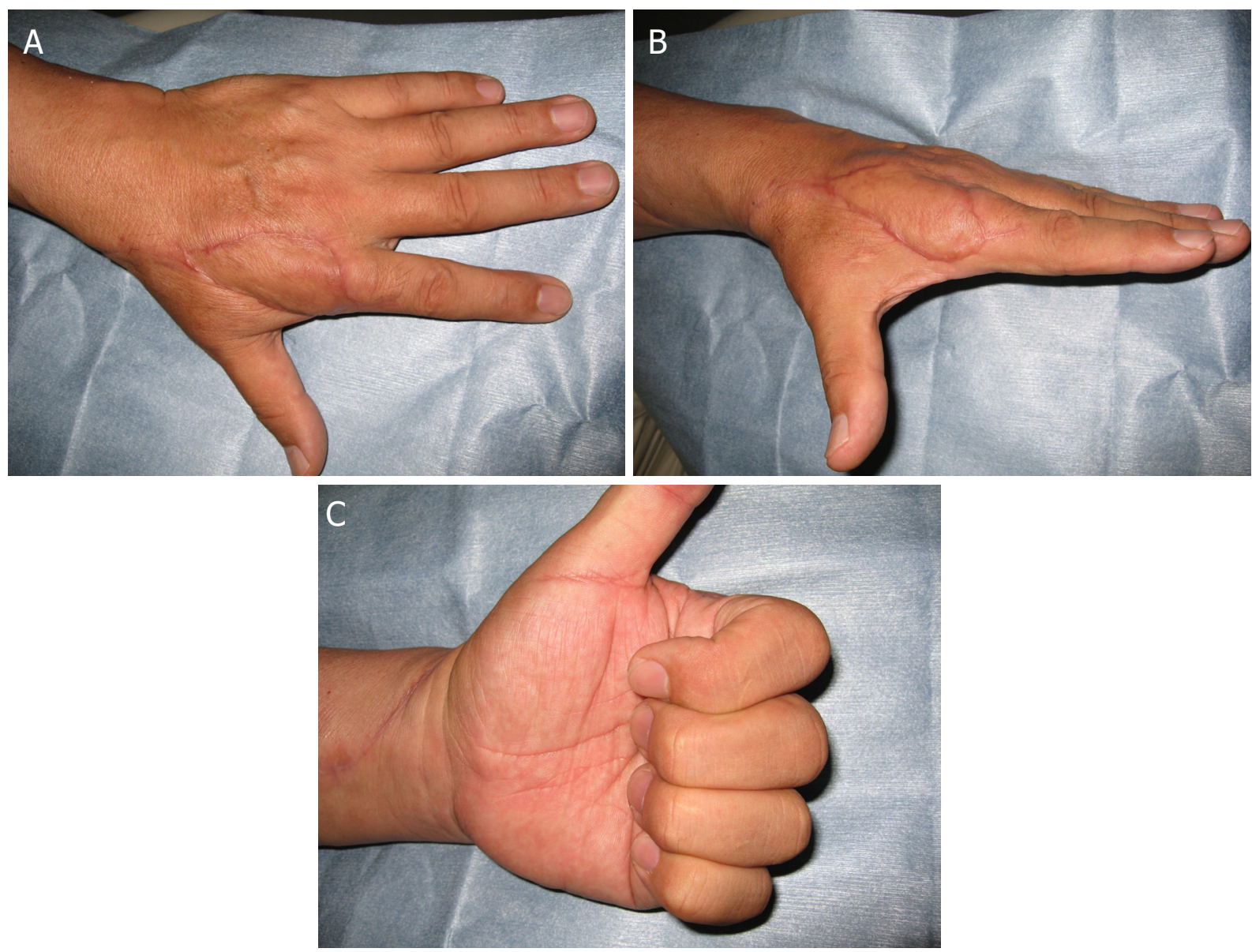

Figure 8. A 62-year-old man 10 months after reconstructive surgery for dorsal hand skin and extensor tendon defects. A: the color matching was good; B: extension of the index finger was close to full; C: all index finger joints have slightly limited flexion

Currently, distant, free, or local flaps are generally used to cover dorsal hand defects [Table 1]. Distant flaps, including abdominal, groin, and intercostalis flaps, are simple and good options for large defects ${ }^{[12-14]}$. However, they require at least two surgeries and prolonged recovery periods. Although blood supply of these flaps is reliable, the risks of elbow or shoulder contracture are higher than other options due to the prolonged recovery period. In addition, it is difficult to reconstruct thin and pliable skin.

Free flaps, including anterolateral thigh flaps, lateral arm flaps, and scapular flaps, enable one-step reconstruction ${ }^{[15]}$. Moreover, donor site morbidity can be minimized, and the extensor digitorum tendon and its gliding surface can be reconstructed as required. Muneuchi et al ${ }^{[16]}$ reported that a free anterolateral thigh fasciocutaneous flap was useful to fill the dead space of a dorsal hand defect after resection of the bursa, and the flap also aided in reconstructing a two-layer gliding surface of the extensor tendons. However, as the arteries and veins are usually damaged, anastomosis of vessels is problematic.

Local flaps, including the retrograde posterior interosseous flaps and retrograde forearm flaps, have good color and texture matching for dorsal hand reconstruction ${ }^{[17]}$. However, retrograde posterior interosseous flaps require meticulous dissection and the posterior interosseous artery in the middle of the forearm varies. Furthermore, the presence of distal communication between the posterior interosseous artery and the anterior interosseous artery must be confirmed ${ }^{[17]}$. If communication between the two vessels is unsatisfactory, this flap cannot be used for reconstruction. Moreover, retrograde posterior interosseous flaps have been reported to have relatively high complication rates such as flap necrosis ${ }^{[18-20]}$. 
Table 1. Flap options for reconstruction of dorsal hand defects

\begin{tabular}{|c|c|c|c|}
\hline Flap options & Advantages & Disadvantages & Representative flaps \\
\hline Distant flap & $\begin{array}{l}\text { Technically simple procedure } \\
\text { High reliability of blood supply }\end{array}$ & $\begin{array}{l}\text { Relatively longer down-time } \\
\text { High risk of joint contracture } \\
\text { Requires at least two surgeries } \\
\text { Inability to reconstruct tendons } \\
\text { Bulky }\end{array}$ & $\begin{array}{l}\text { Abdominal flap } \\
\text { Groin flap }\end{array}$ \\
\hline Free flap & $\begin{array}{l}\text { Reconstruction in one surgery } \\
\text { Low donor site morbidity and risk of } \\
\text { joint contracture } \\
\text { Tendon reconstruction is possible }\end{array}$ & Technically complex & $\begin{array}{l}\text { Free anterolateral thigh flap } \\
\text { Free peroneal flap } \\
\text { Free groin flap }\end{array}$ \\
\hline Local flap & $\begin{array}{l}\text { Good color and texture matching } \\
\text { Requires no microvascular anastomosis }\end{array}$ & $\begin{array}{l}\text { Requires retrograde blood flow } \\
\text { High risk of donor site morbidity when } \\
\text { a large flap is harvested }\end{array}$ & $\begin{array}{l}\text { Retrograde posterior interosseous flap } \\
\text { Retrograde forearm flap }\end{array}$ \\
\hline
\end{tabular}

Table 2. Advantages and disadvantages of representative local flaps and the radial artery perforator-based adipofascial flap

\begin{tabular}{|c|c|c|}
\hline Local flaps & Advantages & Disadvantages \\
\hline $\begin{array}{l}\text { Retrograde posterior } \\
\text { interosseous flap }\end{array}$ & $\begin{array}{l}\text { Good color and texture matching } \\
\text { Low risk of donor site morbidity }\end{array}$ & $\begin{array}{l}\text { Requires meticulous dissection Relatively high } \\
\text { complication rate } \\
\text { Limitation of flap size }\end{array}$ \\
\hline Retrograde forearm flap & $\begin{array}{l}\text { Technically easier than the retrograde posterior } \\
\text { interosseous flap } \\
\text { Tendon reconstruction is possible }\end{array}$ & $\begin{array}{l}\text { Requires sacrifice of the main artery } \\
\text { High risk of donor site dysfunction }\end{array}$ \\
\hline $\begin{array}{l}\text { Radial artery perforator- } \\
\text { based adipofascial flap }\end{array}$ & $\begin{array}{l}\text { Retrograde blood flow is not needed } \\
\text { Sacrificing main artery is not required } \\
\text { Donor site morbidities are minimal } \\
\text { Possible to reconstruct thin dorsal hand by skin grafting } \\
\text { Tendon reconstruction is possible } \\
\text { Simple and short surgery }\end{array}$ & $\begin{array}{l}\text { Temporary pain due to fascial traction } \\
\text { Skin graft is needed }\end{array}$ \\
\hline
\end{tabular}

Taghinia et al. ${ }^{[3]}$ recommended a retrograde radial forearm adipofascial flap to avoid functional problems caused by adhesion at the donor site. Although this flap is technically easier to use than the retrograde posterior interosseous flap, it has the disadvantage of sacrificing the main artery. In certain cases, such as Allen test-negative, this flap is not applicable because it requires retrograde blood flow.

In 1989, Koshima et al. ${ }^{[21]}$ reported inferior epigastric artery skin flaps without rectus abdominis muscle and called them perforator flaps. Since then, many perforator flaps have been developed. The radial artery perforator-based flap is one, which does not require retrograde blood flow and can be applied to hand reconstruction without sacrificing major vessel ${ }^{[22,23]}$. Donor site problems can be minimized by using this flap as an adipofascial flap ${ }^{[2-24]}$. In addition, the thin and pliable dorsal hand skin can be reconstructed by performing skin grafting over the adipofascial flap. The extensor digitorum tendon can be reconstructed by including the tendon, such as the palmaris longus or brachioradialis tendon, in the adipofascial flap as described in Case $2^{[23,25]}$. Furthermore, this flap has a great advantage in that the procedure is simple and can be completed in a short time ${ }^{[23,24,26]}$. Although the patients may complain about pain due to fascial traction, it disappeared in approximately one month in our cases. The advantages and disadvantages of representative local flaps and radial artery perforator-based adipofascial flaps are summarized in Table 2.

\section{CONCLUSION}

The radial artery perforator-based adipofascial flap is an excellent functional reconstructive option for complex dorsal hand defects with minimal donor site morbidity.

\section{DECLARATIONS}

\section{Authors' contributions}

Contributed to data acquisition and also provided administrative, technical, and material support: Yamakawa S, Hayashida K

Reviewed the manuscript for content and grammar/spelling mistakes: Yamakawa S, Hayashida K 


\section{Availability of data and materials}

Not applicable.

\section{Financial support and sponsorship}

None.

\section{Conflicts of interest}

All authors declared that there are no conflicts of interest.

\section{Ethical approval and consent to participate}

Written informed consent was obtained from both subjects to participate in this case report. A copy of the written consent is available for review upon request.

\section{Consent for publication}

Written informed consent was obtained from both subjects for publication of this case report and accompanying images. A copy of the written consent is available for review upon request.

\section{Copyright}

(c) The Author(s) 2020.

\section{REFERENCES}

1. Zhang G, Su H, Ju J, Li X, Fu Y, et al. Reconstruction of dorsal and palmar defects of hand with anterolateral thigh flaps from one donor site. J Plast Reconstr Aesthet Surg 2019;72:1917-22.

2. Medalie DA. Perforator-based forearm and hand adipofascial flaps for the coverage of difficult dorsal hand wounds. Ann Plast Surg 2002;48:477-83.

3. Taghinia AH, Carty M, Upton J. Fascial flaps for hand reconstruction. J Hand Surg Am 2010;35:1351-5.

4. Doğan T, Gürünlüoğlu R, Imer B, Numanoğlu A. The distally based forearm island flap in hand reconstruction. Plast Reconstr Surg 1999;104:1581-2.

5. Suzuki S, Iwamoto T, Koshima I. Adipofascial turnover perforator flap for dorsal hand reconstruction based on both the posterior interosseous artery and radial artery. J Hand Surg Eur Vol 2012;37:178-80.

6. El-Sabbagh AH, Zeina AA, El-Hadidy AM, El-Din AB. Reversed posterior interosseous flap: safe and easy method for hand reconstruction. J Hand Microsurg 2011;3:66-72.

7. Sham E, Masia JA, Reddy TJ. Vascular analysis of radial artery perforator flaps. Ann Maxillofac Surg 2018;8:66-72.

8. Saint-Cyr M, Mujadzic M, Wong C, Hatef D, Lajoie AS, et al. The radial artery pedicle perforator flap: vascular analysis and clinical implications. Plast Reconstr Surg 2010;125:1469-78.

9. Onode E, Takamatsu K, Shintani K, Yokoi T, Uemura T, et al. Anatomical origins of radial artery perforators evaluated using color Doppler ultrasonography. J Reconstr Microsurg 2016;32:594-8.

10. Taylor GI, Chubb DP, Ashton MW. True and 'choke' anastomoses between perforator angiosomes: part i. anatomical location. Plast Reconstr Surg 2013;132:1447-56.

11. Sananpanich K, Tu YK, Kraisarin J, Chalidapong P. Reconstruction of limb soft-tissue defects: using pedicle perforator flaps with preservation of major vessels, a report of 45 cases. Injury 2008;39:55-66.

12. Nazerani S, Motamedi MH, Nazerani T, Bidarmaghz B. Treatment of traumatic degloving injuries of the fingers and hand: introducing the “compartmented abdominal flap". Tech Hand Up Extrem Surg 2011;15:151-5.

13. McGregor IA, Jackson IT. The groin flap. Br J Plast Surg 1972;25:3-16.

14. Gao JH, Hyakusoku H, Inoue S, Aoki R, Kanno K, et al. Usefulness of narrow pedicled intercostal cutaneous perforator flap for coverage of the burned hand. Burns 1994;20:65-70.

15. Griffin M, Hindocha S, Malahias M, Saleh M, Juma A. Flap decisions and options in soft tissue coverage of the upper limb. Open Orthop J 2014;8:409-14.

16. Muneuchi G, Suzuki S, Ito O, Kawazoe T. Free anterolateral thigh fasciocutaneous flap with a fat/fascia extension for reconstruction of tendon gliding surface in severe bursitis of the dorsal hand. Ann Plast Surg 2002;49:312-6.

17. Liu DX, Wang H, Li XD, Du SX. Three kinds of forearm flaps for hand skin defects: experience of 65 cases. Arch Orthop Trauma Surg 2011;131:675-80.

18. Büchler U, Frey HP. Retrograde posterior interosseous flap. J Hand Surg Am 1991;16:283-92.

19. Lu LJ, Gong X, Lu XM, Wang KL. The reverse posterior interosseous flap and its composite flap: experience with 201 flaps. J Plast Reconstr Aesthet Surg 2007;60:876-82. 
20. Akinci M, Ay S, Kamiloglu S, Erçetin O. The reverse posterior interosseous flap: a solution for flap necrosis based on a review of 87 cases. J Plast Reconstr Aesthet Surg 2006;59:148-52.

21. Koshima I, Soeda S. Inferior epigastric artery skin flaps without rectus abdominis muscle. Br J Plast Surg 1989;42:645-8.

22. Weinzweig N, Chen L, Chen ZW. The distally based radial forearm fasciosubcutaneous flap with preservation of the radial artery: an anatomic and clinical approach. Plast Reconstr Surg 1994;94:675-84.

23. Chang SM, Hou CL, Zhang F, Lineaweaver WC, Chen ZW, et al. Distally based radial forearm flap with preservation of the radial artery: anatomic, experimental, and clinical studies. Microsurgery 2003;23:328-37.

24. Koshima I, Moriguchi T, Etoh H, Tsuda K, Tanaka H. The radial artery perforator-based adipofascial flap for dorsal hand coverage. Ann Plast Surg 1995;35:474-9.

25. Appleton SE, Morris SF. Anatomy and physiology of perforator flaps of the upper limb. Hand Clin 2014;30:123-35.

26. Samson D, Power DM. The adipofascial radial artery perforator flap: a versatile reconstructive option in upper limb surgery. Hand Surg 2015;20:266-72. 